\title{
Identification and Prevalence of Botrytis spp. from Blackberry and Strawberry Fields of the Carolinas
}

Xingpeng Li, Dolores Fernández-Ortuño, and Wenxuan Chai, School of Agricultural, Forestry \& Life Sciences, Clemson University, Clemson, SC 29634; Fei Wang, Department of Plant Pathology, College of Plant Sciences and Technology and the Key Lab of Crop Disease Monitoring \& Safety Control, Hubei Province, Huazhong Agricultural University, Wuhan, China; and Guido Schnabel, School of Agricultural, Forestry \& Life Sciences, Clemson University

\begin{abstract}
Li, X., Fernández-Ortuño, D., Chai, W., Wang, F., and Schnabel, G. 2012. Identification and prevalence of Botrytis spp. from blackberry and strawberry fields of the Carolinas. Plant Dis. 96:1634-1637.

Gray mold disease of blackberry and strawberry is caused by Botrytis cinerea and B. caroliniana in the southeastern United States. In this study, methods to distinguish both species were established and their prevalence was determined in commercial blackberry and strawberry fields. Using DNA from $B$. cinerea and $B$. caroliniana reference strains, a species-differentiating polymerase chain reaction (PCR) amplification was developed that amplified G3PDH gene fragments of two different sizes depending on the species. The PCR is performed with three primers (two species-differentiating forward primers and one universal reverse primer) and amplified a 238-bp product from $B$. cinerea and a 536-bp fragment from $B$. caroliniana reference isolates. A total of 400 Botrytis isolates were collected from 6 commercial

blackberry and 11 strawberry fields of the Carolinas and identified to the species level by the new PCR method. Both Botrytis spp. were identified in blackberry and strawberry fields, but $B$. caroliniana was less common than $B$. cinerea. Only 33 of 202 isolates from blackberry fields were identified as $B$. caroliniana, and the majority of these isolates came from two fields in South Carolina. Only 1 of 198 isolates from strawberries was identified as $B$. caroliniana, and this isolate was found in central North Carolina. B. cinerea but not $B$. caroliniana isolates sporulated on potato dextrose agar and Kings medium B. Our results show that $B$. cinerea and $B$. caroliniana coexist in at least some commercial blackberry and strawberry fields of the Carolinas, with $B$. cinerea being the more prevalent species.
\end{abstract}

Among the economically most important small fruit crops in the southeastern United States affected by gray mold disease are strawberries (Fragaria $\times$ ananassa) and blackberries (Rubus). In 2010, more than 950 ha of strawberries were planted in North and South Carolina valued at about $\$ 30$ million (15). Other states in the Southeast with significant strawberry production include Florida, Georgia, and Tennessee. Almost all commercial strawberries are produced with the plasticulture annual cropping system. In the Carolinas, plants are typically obtained from nurseries, planted in September or October, and cropped in the spring and early summer of the following year. In contrast, blackberries have biennial canes and perennial roots, and the same planting may be cropped for a decade or longer. Often, winter injury and cool temperatures create ideal conditions for gray mold disease in both crops.

Botrytis cinerea Pers. is the causal agent of tissue blight, rots, and gray mold disease of over 200 plant species including strawberry and blackberry (17). B. cinerea generally overwinters in decaying plant debris or as sclerotia. The pathogen prefers cool and moist weather conditions for infection and for postinfection disease development (18). In the plant, the pathogen may remain latent if disease development conditions are unfavorable. Eventually, the pathogen triggers host-cell death, which causes the progressive decay of infected petals, leaves, fruit, and various other plant tissues. On the surface of infected tissue, it produces abundant conidia, which can be transported by wind over long distances. B. cinerea also has a sexual, teleomorphic stage named Botrytis fuckeliana (9).

Although $B$. cinerea has been recognized to be a complex of species in Europe (5), it was until recently considered the only

Corresponding author: Guido Schnabel, E-mail: schnabe@clemson.edu

Accepted for publication 25 May 2012.

http://dx.doi.org/10.1094/PDIS-02-12-0128-RE

(C) 2012 The American Phytopathological Society species causing gray mold of small fruits in the United States. A new species designated Botrytis caroliniana X.P. Li \& G. Schnabel was isolated in 2010 from blackberry fruit in South Carolina (10), adding to the Botrytis spp. list in North America. Based on phylogenetic and morphological analysis, B. caroliniana is most closely related to B. fabiopsis (19), a broad bean (Vicia faba) pathogen from Central China (20), and $B$. galanthina $(8,14)$, a species isolated from snowdrop (Galanthus spp.), a bulbous herbaceous plants. The prevalence and host range of $B$. caroliniana is unknown, but it is becoming increasingly clear that this species causes disease on various small fruits, including blackberry and strawberry $(3,10)$.

The objective of this study was to develop simple and reliable tools to distinguish $B$. caroliniana from $B$. cinerea and to determine the prevalence of the two species in commercial blackberry and strawberry fields of the Carolinas.

\section{Materials and Methods}

Origin of isolates. Isolates from symptomatic blackberry fruit were collected in the fall of 2010 and 2011 from commercial fields in Oconee (isolate code CB), Anderson (isolate code CA), Pickens (isolate code WM), Chesterfield (isolate code MC), and Chesnee counties (isolate code CO) in South Carolina, and Cleveland County (isolate code KC) in North Carolina. Isolates collected in 2011 are indicated with an "a" following the isolate code. The isolates from strawberries were collected from commercial fields in Cleveland (isolate code SBY), Duplin (isolate code NC), Guilford (isolate code HP), and Iredell counties (isolate code MV) in North Carolina and Aiken (isolate code GIK), Cherokee (isolate code JEY), Chesterfield (isolate code KUD), Florence (isolate code FLOR), Lexington (isolate code MER), Saluda (isolate code WIC), and Spartanburg counties (isolate code MOD) in South Carolina. All isolates from blackberry and strawberry fields came from individual fruits of different plants. Each fruit was placed in an individual plastic bag after harvest and stored at $4{ }^{\circ} \mathrm{C}$ for up to 5 days prior to single-spore isolation. Three B. cinerea isolates (CA25, CB17, and WM6) and three B. caroliniana reference isolates (CA3, 
CB15, and WM4) originally obtained from blackberry fruit (10) were included in this study. They are designated "reference isolates" because they were characterized in a previous study (10).

Development of a species-differentiating polymerase chain reaction (PCR) assay. Three primers targeting a partial sequence of the glyceraldehydes-3-phosphate dehydrogenase (G3PDH) gene were designed based on sequences published from $B$. cinerea and $B$. caroliniana reference isolates (Table 1). Forward primers G3PDH-F1 and G3PDH-F2 are specific for $B$. caroliniana and $B$. cinerea, respectively, and were used with reverse primer G3PD-R for species-differentiating DNA amplification. Genomic DNA was extracted as described previously (2). PCR amplification was performed in a total reaction volume of $50 \mu$ l. The following compounds were added, with final concentrations indicated: $1 \times$ ThermoPol reaction buffer (BioLabs, Ipswich, MA), dNTPs $(0.25$ $\mathrm{mM}$ of each dATP, dGTP, dCTP, dTTP; BioLabs), 0.6 pmol $\mu \mathrm{l}^{-1}$ of each primer (Table 1), Taq DNA polymerase (1.25 units; BioLabs), and 10 to $100 \mathrm{ng}$ of fungal DNA. The following thermocycling protocol was used to amplify the $G 3 P D H$ fragment: $94^{\circ} \mathrm{C}$ for 3 $\min (1 \mathrm{cycle}) ; 94^{\circ} \mathrm{C}$ for $30 \mathrm{~s}, 56^{\circ} \mathrm{C}$ for $30 \mathrm{~s}$, and $72^{\circ} \mathrm{C}$ for $1 \mathrm{~min}(32$ cycles); and $72^{\circ} \mathrm{C}$ for 5 min ( 1 cycle). Fragments were separated on a $1 \%$ agarose gel, stained with ethidium bromide, and visualized under UV-light. The fragment size of the PCR product was verified by comparison to a Low Range Plus DNA Ladder (Fisher Scientific).

Single-spore isolation and cultural characterization. For single-spore isolation, conidia were scraped off without touching the fruit using a sterile scalpel and suspended in $1 \mathrm{ml}$ of sterile, distilled water with $1 \%$ Tween 60 . Then, $200 \mu$ of the spore suspension were spread on water agar in petri dishes $(90 \mathrm{~mm}$ diameter) amended with lactic acid $(0.1 \%$, vol/vol $)$ and streptomycin $(100 \mu \mathrm{g} / \mathrm{ml})$. After incubation at $22^{\circ} \mathrm{C}$ for 24 to $36 \mathrm{~h}$, three germinated conidia were scooped up by a glass needle under a microscope and placed $2 \mathrm{~cm}$ apart in equal distances onto potato dextrose agar (Difco Laboratories, Sparks, MD) amended with streptomycin $(100 \mu \mathrm{g} / \mathrm{ml})$ and propiconazole $(0.1 \mu \mathrm{g} / \mathrm{ml})$, and petri dishes were incubated at $22^{\circ} \mathrm{C}$ for $36 \mathrm{~h}$. One of the three singlespore colonies was kept for further studies.

To investigate spore production ability in vitro, agar plugs (6 $\mathrm{mm}$ diameter) containing actively growing mycelium were placed on Kings medium B (KMB: 20 g Proteose Peptone No. 3 (Difco), $1.5 \mathrm{~g} \mathrm{~K}_{2} \mathrm{HPO}_{4}, 0.738 \mathrm{~g} \mathrm{MgSO}_{4}$ (anhydrous), $15 \mathrm{~g}$ agar, $10 \mathrm{ml}$ glycerol, and $990 \mathrm{ml}$ water for 1 liter of medium) (1) and PDA with the mycelia side down. KMB was used previously to produce conidia from $B$. cinerea cultures for experimental purposes (4). Plates were incubated at $20^{\circ} \mathrm{C}$ for 7 days at 12-h intervals of fluorescent light and darkness. Conidiophores and conidia were observed on plates with sporulating isolates but not on plates with nonsporulating isolates.

DNA extraction and PCR amplification of G3PDH, HSP6O, and $R P B 2$ gene fragments. While most $B$. cinerea isolates sporulated heavily on PDA and KMB, isolate WM8a sporulated weakly on both media and was therefore subjected to more vigorous molecular analysis for species verification. It was isolated from a decayed blackberry fruit collected in a field where both species were present. Genomic DNA was extracted as described previously (2). The partial sequence of the glyceraldehydes-3phosphate dehydrogenase (G3PDH), heat-shock protein 60 (HSP60), and DNA-dependent RNA polymerase subunit II (RPB2) were PCR amplified using primer pairs G3PDHfor/G3PDHrev, HSP60for/HSP60rev, and RPB2for/RPB2rev, respectively (13).

Table 1. Nucleotide sequences of primers designed to distinguish Botrytis cinerea from B. caroliniana

\begin{tabular}{ll}
\hline Name & Nucleotide sequence $\left(\mathbf{5}^{\prime} \mathbf{-} \mathbf{3}^{\prime}\right)$ \\
\hline G3PDH-F1 & GGACCCGAGCTAATTTATGTCACGT \\
G3PDH-F2 & GGGTGTCAACAACGAGACCTACACT \\
G3PDH-R & ACCGGTGCTCGATGGGATGAT \\
\hline
\end{tabular}

The PCR products were purified using the ExoSAP-IT purification kit (USB Corporation, Cleveland, $\mathrm{OH}$ ) following manufacturers recommendations. Purified products were sequenced at Clemson University Genomic Center. Nucleotide sequences were analyzed and aligned with DNASTAR sequence analysis software (DNASTAR, Inc., Madison, WI).

\section{Results}

Distinction of $B$. cinerea and $B$. caroliniana using species-differentiating PCR and cultural characteristics. $B$. cinerea reference isolates CA25, CB17, and WM6 produced a 238-bp fragment with primer set G3PDH-F1, G3PDH-F2, and G3PDH-R. The same primer set produced a 536-bp fragment for $B$. caroliniana reference isolates CA3, WM4, and CB15 (Fig. 1). The species-differentiating PCR was further validated by HSP6O gene sequence analysis. The majority of the HSP60 gene was sequenced from $10 \mathrm{~B}$. cinerea isolates and $10 \mathrm{~B}$. caroliniana isolates from different geographic locations, and sequence analysis verified that the species-differentiating PCR accurately detected isolates to the species level (data not shown). Using this technique, 33 and 1 additional B. caroliniana isolates were identified from blackberries and a single strawberry, respectively (Table 2).

$B$. cinerea reference isolates CA25, WM6, and CB17, as well as $158 \mathrm{~B}$. cinerea isolates from blackberries and 197 isolates from strawberries, sporulated on PDA and KMB media. Isolate WM8a was identified by PCR as $B$. cinerea but sporulated only weakly on PDA and KMB (Fig. 2). The culture characteristics therefore are different from all other sporulating isolates. Subsequent sequence analysis of the $G 3 P D H, R P B 2$, and $H S P 60$ genes confirmed that the gene sequences were identical to $B$. cinerea reference isolate sequences available in GenBank (data not shown; accession numbers JN672671, JN672675, and JN672677, respectively, for isolate CB17; JN164270, JN164271, and JN164272, respectively, for isolate WM6; and JN672672, JN672676, and JN672678, respectively, for isolate CA25). Thus, both sporulation phenotypes observed in this collection of 202 isolates corresponded to the PCRbased species differentiation assay.

Prevalence of $B$. cinerea and $B$. caroliniana isolates in blackberry and strawberry fields of the Carolinas. $B$. cinerea was the dominant species in blackberry and strawberry fields of the Carolinas. Only 33 of $202(16.3 \%)$ isolates from blackberry and only 1 of $198(0.5 \%)$ isolates from strawberry were identified as $B$. caroliniana (Table 2). B. cinerea and B. caroliniana were found to coexist in four of six populations from blackberry fields; three from South Carolina and one from North Carolina. The four fields

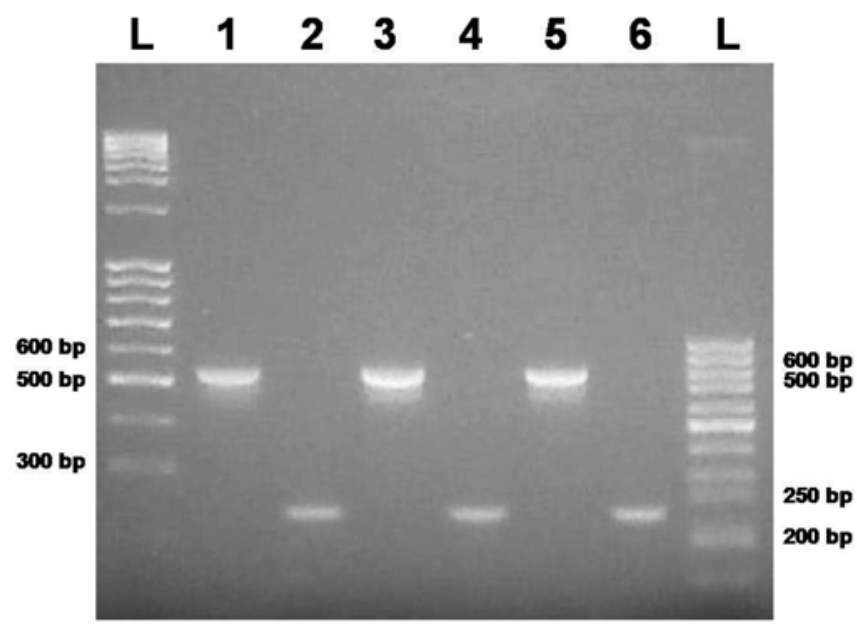

Fig. 1. Amplification of the G3PDH gene fragment with primer set G3PDH-F1, G3PDH-F2, and G3PDH-R followed by electrophoresis on a $1 \%$ agarose gel. Lanes 1,3 , and 5 are Botrytis caroliniana isolates CA3, CB15, and WM4; lanes 2, 4, and 6 are $B$. cinerea isolates CA25, CB17, and WM6; lane $L$ on the left is the Middle Range Plus DNA Ladder (Fisher Scientific, Hampton, NH); lane L on the right is the 50-bp Mini DNA Ladder (Fisher Scientific). 
were located close to the western border of the Carolinas (Fig. 3A). Although isolates from 10 strawberry fields were included in this study, only one located in the center of North Carolina revealed a B. caroliniana isolate (Fig. 3B).

\section{Discussion}

B. caroliniana and B. cinerea are distinct species of Botrytis as determined by phylogenetic analysis of the HSP60, G3PDH, and $R P B 2$ gene sequences and unique cultural characteristics (10). In this follow-up study, we developed and validated tools to more easily distinguish $B$. cinerea from $B$. caroliniana. The molecular distinction based on species-differentiating PCR amplification and the morphological distinction based on sporulation ability on PDA and $\mathrm{KMB}$ provided consistent results for the reference isolates and all 400 isolates obtained from strawberries and blackberries for this study. While our data indicate a strong correlation between species and sporulation ability on PDA and KMB, the cultural characteris- tics should not be used as a sole indicator for a species. That is because sporulation intensity varied among isolates, and weak sporulators of the $B$. cinerea species may therefore be mistaken for B. caroliniana. For example, isolate WM8a sporulated only weakly, whereas all other $B$. cinerea isolates sporulated profusely on PDA and KMB media. HSP60, G3PDH, and RPB2 gene sequence analysis, however, confirmed this isolate to be $B$. cinerea. Furthermore, it is possible that variability in the population may produce nonsporulating $B$. cinerea and/or sporulating $B$. caroliniana in other locations.

Our results are consistent with other observations identifying $B$. cinerea to be a species complex (5). In the latter study, B. pseudocinerea was identified to be a part of this complex (16) in Europe. This species is genetically closely related to $B$. cinerea based on phylogenetic analysis of the HSP6O and G3PDH genes and is therefore only distantly related to $B$. caroliniana, which clusters closest to B. galanthina and B. fabiopsis (10). Sympatry of B. ci-

Table 2. Molecular and cultural distinction of Botrytis cinerea and B. caroliniana isolates from blackberry and strawberry

\begin{tabular}{|c|c|c|c|c|c|}
\hline Species & Host & Isolates & $\begin{array}{l}\text { No. } \\
\text { isolates }\end{array}$ & $\begin{array}{l}\text { PCR fragment } \\
\text { size }(b p)^{\mathrm{a}}\end{array}$ & $\begin{array}{c}\text { Sporulation } \\
\text { PDA/KMB }\end{array}$ \\
\hline \multirow[t]{2}{*}{ B. cinerea } & Blackberry & $\begin{array}{l}\text { KC1, KC3-27, KC30-52, WMa1, WMa3-5, WMa8,WMa9, WMa12-14, } \\
\text { WMa17, WMa24, WMa26-27, WMa31, WMa33-35, WMa39-41, WMa44-46, } \\
\text { WMa48, WMa55, WMa57, WMa61, WMa68, WMa71, WMa75, WM6, MC1, } \\
\text { MC5, MC9, MC12-15, MC21-22, MC26-28, MC31-34, COa1, COa3, COa5, } \\
\text { COa7, COa9-18, COa20-21, COa23-24, CO2-4, CO6-8, CO10-12, CO15-17, } \\
\text { CO20-21, CAa3, CA1, CA11, CA25, CB17, CBa1, CBa3-7, CBa10-14, } \\
\text { CBa16-17, CBa19-20, CBa22-23, CBa26-29, CBa31, CBa35-37, CBa40-42, } \\
\text { CBa45, CBa47, CBa49, CBa55, CBa57, CBa60-62 }\end{array}$ & 169 & 238 & Yes \\
\hline & Strawberry & $\begin{array}{l}\text { BC11KUD1-21, BC11MOD2-20, BC11GIK1-6, BC11GIK9-21, BC11JEY1-25, } \\
\text { BC11FLOR1-13, BC11MER1-3, BC11WIC1-21, BC11HP1-30, BC11HP32, } \\
\text { BC11HP34, BC11MV1-2, BC11MV4-6, BC11MV8-11, BC11Sby1-19, } \\
\text { BC11SBY21, BC11SBY23-37 }\end{array}$ & 197 & 238 & Yes \\
\hline \multirow[t]{2}{*}{ B. caroliniana } & Blackberry & $\begin{array}{l}\text { KC29, WM4, WMa6-7, WMa18, WMa22, WMa30, WMa32, WMa47, } \\
\text { WMa62, WMa64, WMa67, WMa72, CAa2, CA3, CA8, CA9, CBa2, CBa8-9, } \\
\text { CBa24, CBa30, CBa33, CBa34, CBa39, CBa46, CBa48, CBa51-54, CB9, } \\
\text { CB15 }\end{array}$ & 33 & 536 & No \\
\hline & Strawberry & BC11HP33 & 1 & 536 & No \\
\hline
\end{tabular}

a Polymerase chain reaction (PCR) fragment was amplified with primers G3PDH-F1, G3PDH-F2, and G3PDH-R in a single reaction.

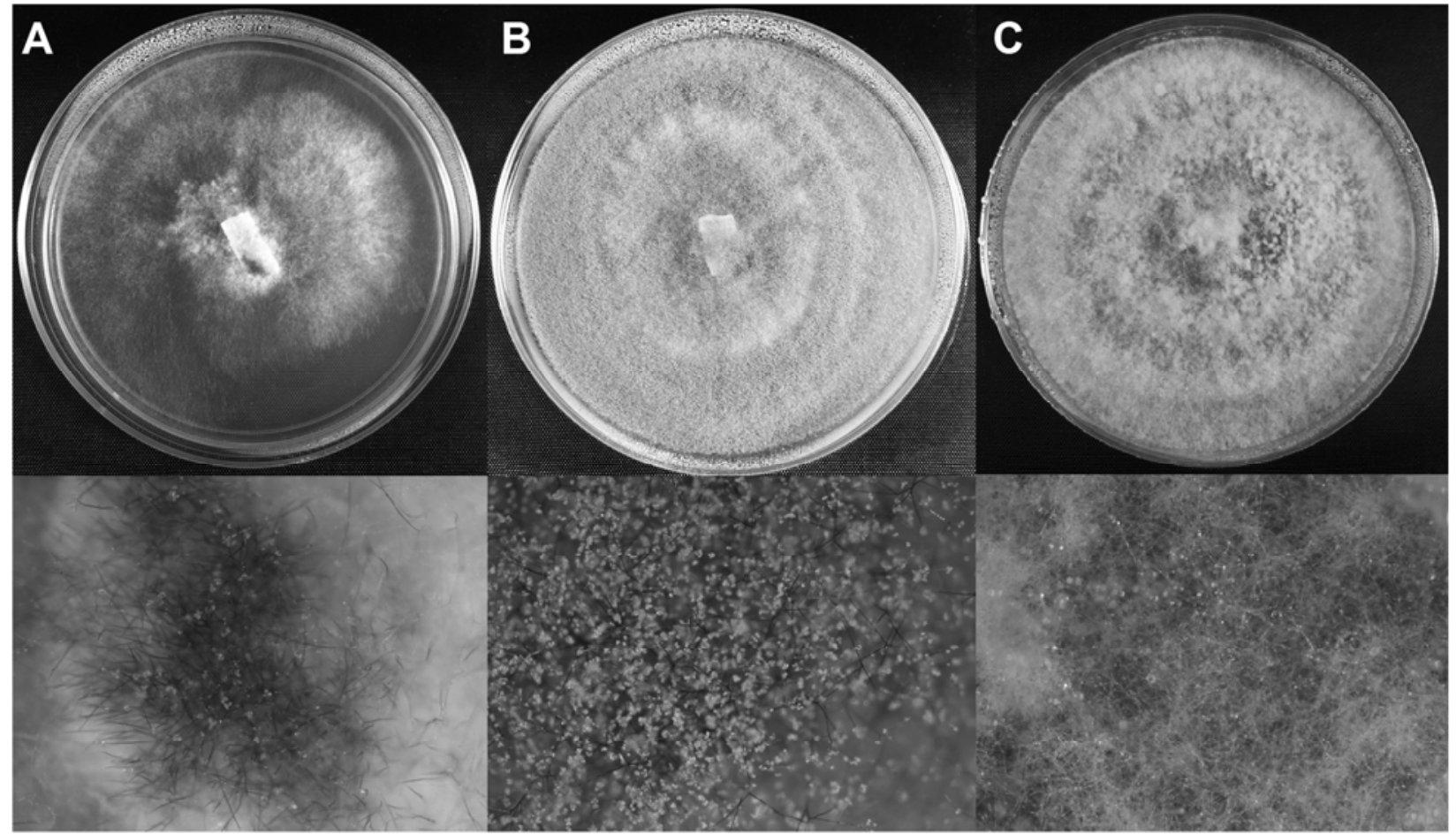

Fig. 2. Cultural characteristics of $\mathbf{A}$, weakly sporulating Botryits cinerea isolate WM8a, $\mathbf{B}$, abundantly sporulating respresentative isolate MC31, and $\mathbf{C}$, $B$. caroliniana isolate CB15 after 6 days of incubation on potato dextrose agar at $22^{\circ} \mathrm{C}$ under discontinuous light exposure. 
nerea and $B$. caroliniana was detected in four of six populations; however, it is possible that $B$. caroliniana may have been present in all six populations but escaped collection. Morphologically similar but genetically diverse subspecies of B. cinerea $(3,4)$, Lophodermium pinastrii (12), and Phialocephara fortinii (7) have been shown to inhabit the same ecological niche. Similarly, species of Colletotrichum may co-inhabit certain geographical areas (11). It has also been suggested that $B$. cinerea is a complex of sibling species with similar morphology and a high level of genetic diversity occupying different ecological niches (6). The population genetics analysis revealed a high level of diversity within $B$. cinerea. The present study suggests that $B$. cinerea and $B$. caroliniana, which are morphologically and genetically diverse (10), not only share the same ecological niche; they also share a common host.

$B$. caroliniana was nearly absent in commercial strawberry fields, which may be related to the strawberry production system. Strawberries are annuals and have been produced in plasticulture systems for the last 15 to 20 years. This system, in contrast to matted row culture, calls for rogueing the entire crop after the production season is over and soil fumigation prior to planting. Thus, the field is virtually devoid of gray mold inoculum at planting. Planting material in the form of plugs and bare-root plants derives largely from nurseries in western North Carolina and Prince Edward Island and Ontario provinces of Canada. While inoculum may migrate into strawberry fields from other crops and weeds, gray mold infections may also originate from latent infections in the planting material. The virtual absence of $B$. caroliniana in strawberry fields indicates that strawberry may not be a preferred host of B. caroliniana. Another explanation is that the planting material produced by nurseries may have been devoid of this species. In contrast, blackberries are cropped for many years with roots being perennial and canes being biennial. The two species of Botrytis are therefore much more likely to successfully establish a long-term sympatry in blackberries.
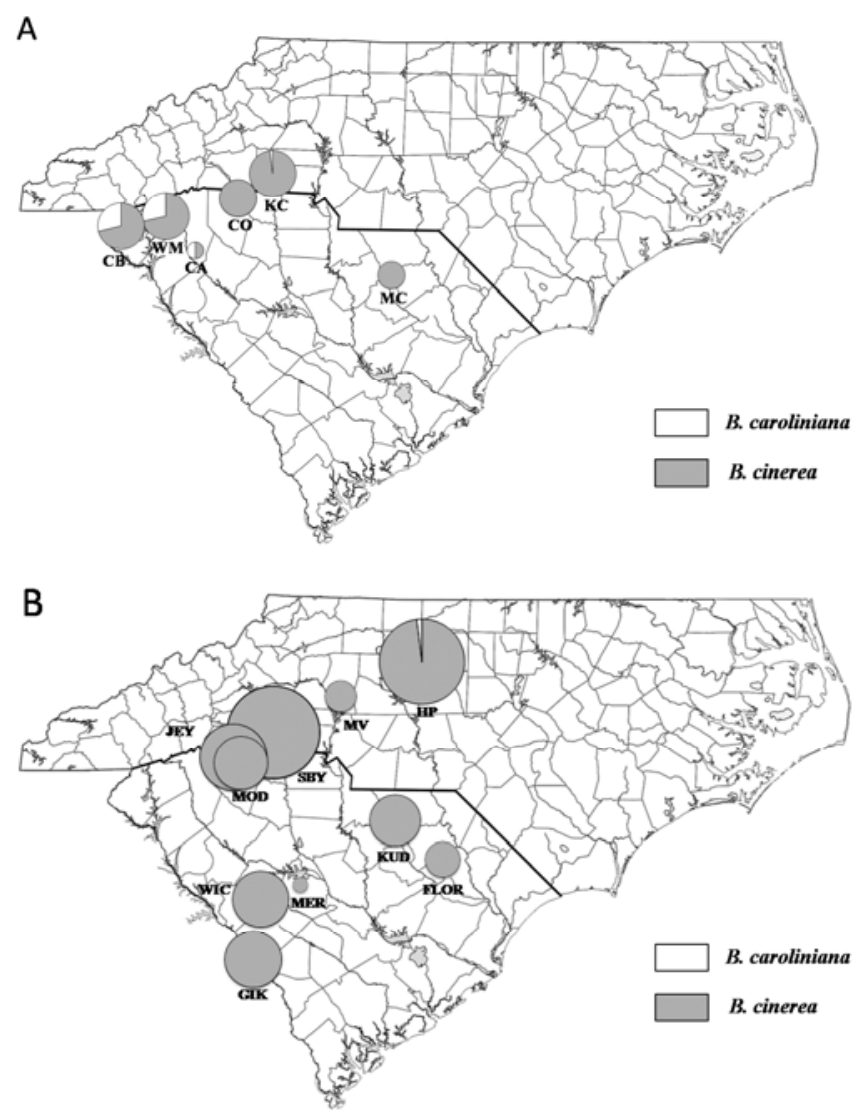

Fig. 3. The origin and prevalence of Botrytis cinerea and $B$. caroliniana isolates from $\mathbf{A}$, blackberry and $\mathbf{B}$, strawberry in the Carolinas. The diameter of each circle is scaled to population size examined.
B. caroliniana occurred overwhelmingly in a cluster of commercial fields located at the most western part of South Carolina. This area is characteristic for its diverse vegetation, including woodlands, wildflowers, ornamentals, wild berries, and more. Furthermore, the three farms with high $B$. caroliniana prevalence contained at the time of collection a variety of fruit crops, including various berry types, which could have served as additional hosts. If the pathogen has more than one preferred host, it is possible that other, still unknown hosts are more abundant in this region compared to other regions in the Carolinas. This would have resulted in high disease pressure and could explain the higher disease incidence on blackberry in this region.

In conclusion, $B$. cinerea and $B$. caroliniana coexist in commercial blackberry and to a lesser degree in commercial strawberry fields of North and South Carolina. The two species can be distinguished using species-differentiating PCR amplification and based on sporulation ability on PDA and KMB.

\section{Acknowledgments}

Technical contribution no. 6014 of the Clemson University Experiment Station. This work was supported by the CSREES/USDA, under project number SC-1000642, and the USDA SCRI Grants Program no. 2010-51181-21113. We thank P. Karen Bryson and Anja Grabke for technical support.

\section{Literature Cited}

1. Atlas, R. M., and Parks, L. C. 1993. Microbiological Media. CRC Press, Boca Raton, FL.

2. Chi, M. H., Park, S. Y., and Lee, Y. H. 2009. A quick and safe method for fungal DNA extraction. Plant Pathol. J. 25:108-111.

3. Fernandez-Ortuno, D., Li, X. P., Wang, F., and Schnabel, G. First report of gray mold of strawberry caused by Botrytis caroliniana in North Carolina. Plant Dis. In press.

4. Forster, H., Kanetis, L., and Adaskaveg, J. E. 2004. Spiral gradient dilution, a rapid method for determining growth responses and 50\% effective concentration values in fungus-fungicide interactions. Phytopathology 94:163-170.

5. Fournier, E., Giraud, T., Albertini, C., and Brygoo, Y. 2005. Partition of the Botrytis cinerea complex in France using multiple gene genealogies. Mycologia 97:1251-1267.

6. Giraud, T., Fortini, D., Levis, C., Lamarque, C., Leroux, P., LoBuglio, K., and Brygoo, Y. 1999. Two sibling species of the Botrytis cinerea complex, transposa and vacuma, are found in sympatry on numerous host plants. Phytopathology 89:967-973.

7. Grunig, C. R., McDonald, M. A., Sieber, T. N., Rogers, S. O., and Holdenrieder, O. 2004. Evidence for subdivision of the root-endophyte Phialocephara fortinii into cryptic species and recombination within species. Fungal Genet. Biol. 41:676-687.

8. Harrison, J. G. 1978. Botrytis galanthina in Scotland. Plant Pathol. 27:145.

9. Hennebert, G. L. 1973. Botrytis and Botrytis-like genera. Persoonia 7:183-204.

10. Li, X. P., Kerrigan, J., Chai, W., and Schnabel, G. 2012. Botrytis carolini$a n a$, a new species isolated from blackberry in South Carolina. Mycologia. In press.

11. Lu, G., Cannon, P. F., Reid, A., and Simmons, C. M. 2004. Diversity and molecular relationships of endophytic Colletotrichum isolates from the Iwokrama Forest Reserve, Guyana. Mycol. Res. 108:53-63.

12. Muller, M. M., Valjakka, R., Suokko, A., and Hantula, J. 2001. Diversity of endophytic fungi of single Norway spruce needles and their role as pioneer decomposers. Mol. Ecol. 10:1801-1810.

13. Staats, M., van Baarlen, P., and van Kan, J. A. L. 2005. Molecular phylogeny of the plant pathogenic genus Botrytis and the evolution of host specificity. Mol. Biol. Evol. 22:333-346.

14. Tsukamoto, T., and Isota, J. 2004. Occurrence of gray mold of Lycoris spp. caused by Botrytis galanthina (Berk. \& Broome) Sacc. and B. cinerea. Jpn. J. Phytopathol. 70:225.

15. U.S. Dep. Agric., Natl. Agric. Stat. Serv. Noncitrus Fruits and Nuts 2010 Summary.

16. Walker, A. S., Gautier, A., Confais, J., Martinho, D., Viaud, M., Pecheur, P. L., Dupont, J., and Fournier, E. 2011. Botrytis pseudocinerea, a new cryptic species causing gray mold in French vineyards in sympatry with Botrytis cinerea. Phytopathology 101:1445.

17. Williamson, B., Tudzynski, B., Tudzynski, P., and van Kan, J. A. L. 2007. Botrytis cinerea: The cause of grey mould disease. Mol. Plant Pathol. 8:561-580.

18. Yohalem, D. S., Nielsen, K., and Nicolaisen, M. 2003. Taxonomic and nomenclatural clarification of the onion neck rotting Botrytis species. Mycotaxon 85:175-182.

19. Zhang, J., Wu, M. D., Li, G. Q., Yang, L., and Jiang, D. H. 2010. Botrytis fabiopsis, a new species causing chocolate spot of broad bean in central China. Mycologia 102:1114-1126.

20. Zhang, J., Zhang, L., Wu, M. D., Li, G. Q., and Jiang, D. H. 2007. Molecular identification of Botrytis species. Proc. Annu. Meeting Chinese Soc. Plant Pathol. 83. 